\section{EASTER VACATION WORK AT PORT ERIN.}

\section{$\mathrm{T}$}

HE Easter vacation party at the Port Erin Biological Station has this year been larger than ever before, and has carried out a longer programme of work-both in the laboratory and on the seashore. During the last few weeks (March and April) the number of researchers and senior students enrolled in the books of the station has reached the record total of eighty-five, including half a dozen professors and a dozen university lecturers and demonstrators, while nearly half of the total number were post-graduate researchers. Altogether twelve universities or university colleges have been represented. Practically all the senior students and post-graduate workers of the botanical and zoological departments of the University of Liverpool, under Profs. Harvey Gibson and Herdman, migrated to the Port Erin laboratory for the vacation. Prof. Cole brought a considerable contingent from the University College of Reading, and Dr. Stuart Thomson a number from Manchester; Mr. Holden came with some students from University College, Nottingham, and smaller groups came from Birmingham, Cambridge, Oxford, Bristol, Bangor, Cardiff, London, and Melbourne. In addition to the laboratory work of the students and their collecting expeditions on the seashore, the activities of the biological station at this time of year are threefold: first, the flat-fish hatching (seen at its best during March and April); secondly, the plankton investigation going on at sea from the s.y. Runa; and thirdly, the special investigations of the post-graduate researchers.

The spawning of the mature plaice in the open-air fish-ponds started at the beginning of February this year, at least a fortnight earlier than usual, and it is by no means finished yet. Already more than eight millions of eggs have been skimmed from the ponds, and about seven millions of young fish have been set free in the sea round the south end of the Isle of Man.

Work at sea was much hampered by bad weather during the earlier part of the time, and it was sometimes difficult to get the periodic plankton hauls taken. This is now the eighth year of Prof. Herdman's scheme of intensive study of the nature and distribution of the plankton, of which it is hoped to complete ten years' statistics before winding up the investigation. Up to the present the phytoplankton this spring has been characterised by the prevalence of Coscinodiscus.

In addition to the collecting and recording of rare species, both of animals and sea-weeds, which has gone on very much as in former years, there has been a large amount of special investigation both at sea and in the laboratory on the part of those who are engaged in the preparation of L.M.B.C. Memoirs, and also of others who are at various researches. For example, Mr. R. D. Laurie has been making observations on the movements of Amphidinium in the sand, Mr. S. T. Burfield has been working at Sagitta, Miss Gleave at Archidoris, Mr. H. G. Jackson on Decapod larvæ in the plankton, and Prof. B. Moore and Mr. E. Whitley on the nutrition of marine animals and the variations in the alkalinity of the sea-water. The memoir on Echinoderm larvæ which Mr. Chadwick has been engaged on for some years is now in the printer's hands, and wili be published at an early date. The pressure on the laboratory accommodation has been very great during this vacation, and the need of further extension of the building is urgent.

NO. 2322, VOL. 93]

W. A. H.
RELATIONS BETWEEN THE SPECTRA AND OTHER CHARACTERISTICS OF THE STARS. *

\author{
I.
}

Historical.

I NVESTIGATIONS into the nature of the stars must necessarily be very largely based upon the average characteristics of groups of stars selected in various ways - as by brightness, proper motion, and the like. The publication within the last few years of a great wealth of accumulated observational material makes the compilation of such data an easy process; but some methods of grouping appear to bring out much more definite and interesting relations than others, and, of all the principles of division, that which separates the stars according to their spectral types has revealed the most remarkable differences, and those which most stimulate attempts at a theoretical explanation.

In the present discussion, I shall attempt to review very rapidly the principal results reached by other investigators, and shall then ask your indulgence for an account of certain researches in which I have been engaged during the past few years.

Thanks to the possibility of obtaining with the objective prism photographs of the spectra of hundreds of stars on a single plate, the number of stars the spectra of which have been observed and classified now exceeds one hundred thousand, and probably as many more are within the reach of existing instruments. The vast majority of these spectra show only dark lines, indicating that absorption in the outer and least dense layers of the stellar atmospheres is the main cause of their production. Even if we could not identify a single line as arising from some known constituent of these atmospheres, we could nevertheless draw from a study of the spectra, considered merely as line-patterns, a conclusion of fundamental importance.

The spectra of the stars show remarkably few radical differences in type. More than 99 per cent. of them fall into one or other of the six great groups which, during the classic work of the Harvard College Observatory, were recognised as of fundamental importance, and received as designations, by the process of "survival of the fittest," the rather arbitrary series of letters B, A, F, G, K, and M. That there should be so few types is noteworthy; but much more remarkable is the fact that they form a continuous series. Every degree of gradation, for example, between the typical spectra denoted by $\mathrm{B}$ and $\mathrm{A}$ may be found in different stars, and the same is true to the end of the series, a fact recognised in the familiar decimal classification, in which $\mathrm{B}_{5}$, for example, denotes a spectrum half-way between the typical examples of $\mathrm{B}$ and $\mathrm{A}$. This series is not merely continuous; it is linear. There exist indeed slight differences between the spectra of different stars of the same spectral class, such as $\mathrm{AO}$; but these relate to minor details, which usually require a trained eye for their detection, while the difference between successive classes, such as A and F, are conspicuous to the novice. Almost all the stars of the small outstanding minority fall into three other classes, denoted by the letters $\mathrm{O}, \mathrm{N}$, and $\mathrm{R}$. Of these $\mathrm{O}$ undoubtedly precedes $B$ at the head of the series, while $R$ and $N$, which grade into one another, come probably at its other end, though in this case the transition stages, if they exist, are not yet clearly worked out.

From these facts it may be concluded that the prin-

* An address delivered before a joint meeting of the Astronomical and Astrophysical Society of America and Sertion A of the American Association for the Advancement of Scrence, at Atlanta, Georgia, December 30, $193_{3}$ for the Advancement of Scrence, at Atlanta,
with a few additions, by Prof. H. N. Rus ell. with a few a 